\title{
PREFERENSI WISATAWAN NUSANTARA MEMILIH HOTEL BERBINTANG DI DAERAH ISTIMEWA YOGYAKARTA
}

\author{
Devy Dwi Fajri ${ }^{1}$, J. Damanik ${ }^{2}$ \\ Sekolah Tinggi Pariwisata AMPTA, Yogyakarta ${ }^{1}$ \\ Fakultas Ilmu Sosial dan Politik, Universitas Gadjah Mada, Yogyakarta ${ }^{2}$ \\ Email:devydwifajri@gmail.com ${ }^{\mathbf{1}}$,antondmk@ugm.ac.id ${ }^{2}$
}

\begin{abstract}
In recent years, there is significant increase of hotel industry in Daerah Istimewa Yogyakarta (DIY), specifically star hotel. The room growth of star hotel from 2014-2018 continuously increases. Based on hotels' Room Occupancy Rate (ROR), star hotels averagely have higher ROR compared to the non star ones. It shows that star hotels' market segment is potential to be developed. Thus, the approach from tourists' side is needed to find out what factors that influence or distinguish tourist preference who use star hotels. Survey is applied as the method to figure out tourist preference. The study focuses on the number of tourists who use star hotel, here is a domestic tourist. The result shows that based on the age, gender, occupation, travel type of domestic tourists there are differences of their preference in service, main facility (room), and additional hotel facility. Afterwards, based on the origin, there is no difference of preference found in tourist attraction choices and length of stay from domestic tourists towards location, service, main facility, and additional hotel facility choices. The findings are expected to give feedbacks for hotel managers in determining strategic steps of star hotel development in order to be sustainable.
\end{abstract}

Keywords: hotel preference; tourist preference; hotel sustainability

\begin{abstract}
ABSTRAK
Industri hotel di Daerah Istimewa Yogyakarta (DIY) beberapa tahun terakhir mengalami pertumbuhan yang signifikan, khususnya hotel berbintang. Pertumbuhan kamar hotel berbintang pada tahun 2014 2018 terus mengalami peningkatan. Berdasarkan tingkat penghunian kamar (TPK) hotel, hotel berbintang memiliki rata-rata TPK yang lebih tinggi dibandingkan dengan hotel nonbintang. Hal ini menunjukkan bahwa segmen pasar hotel berbintang sangat potensial untuk dikembangkan. Dengan demikian, diperlukan pendekatan dari sisi wisatawan untuk mengetahui faktor apa yang memengaruhi atau membedakan preferensi wisatawan menggunakan hotel berbintang sehingga dapat diketahui spesifikasinya seperti apa yang disukai oleh wisatawan. Metode survei digunakan untuk mengetahui preferensi wisatawan. Fokus penelitian merupakan wisatawan terbanyak pengguna hotel berbintang, yaitu wisatawan Nusantara (wisnu). Hasil penelitian menunjukkan bahwa wisnu pengguna hotel berbintang memiliki latar belakang demografi yang luas dan beragam. Berdasarkan usia, jenis kelamin, pekerjaan, dan mode perjalanan wisnu terdapat perbedaan preferensi wisnu pada layanan, fasilitas utama (kamar), dan fasilitas tambahan hotel. Selanjutnya berdasarkan daerah asal, pilihan objek wisata dan lama tinggal wisnu tidak ditemukan adanya perbedaan preferensi terhadap pilihan lokasi, layanan, fasilitas utama, dan fasilitas tambahan hotel. Hasil temuan ini diharapkan dapat memberikan masukan kepada pengelola hotel untuk menentukan langkah strategis pengembangan hotel berbintang agar dapat terus berkelanjutan.
\end{abstract}

Kata kunci: pemilihan hotel; preferensi wisatawan; keberlanjutan hotel 


\section{PENDAHULUAN}

Pariwisata

Daerah Istimewa

Yogyakarta (DIY) beberapa tahun terakhir terus mengalami peningkatan. Hal ini ditandai dengan peningkatan jumlah kunjungan wisatawan. Wisatawan yang berkunjung ke DIY didominasi oleh wisatawan Nusantara (wisnu). Peningkatan jumlah wisatawan berdampak pada peningkatan berbagai jenis usaha pariwisata, salah satunya usaha hotel. Hotel merupakan sarana akomodasi yang cukup penting untuk menunjang kegiatan pariwisata. Pertumbuhan kamar hotel yang ada di DIY dalam kurun waktu 2014-2018 mengalami peningkatan sebesar 15\% (Dinpar DIY, 2019). Laju pertumbuhan kamar hotel berbintang mengalami peningkatan sebesar $32 \%$ per tahun, sedangkan hotel nonbintang hanya sebesar 5\% per tahun. Selanjutnya, tingkat hunian kamar hotel berbintang selama tahun 2014-2018 juga menunjukkan persentase yang lebih tinggi, yaitu sebesar $64,37 \%$, sedangkan hotel nonbintang hanya sebesar 39,46\% (Dinpar DIY, 2019). Hal ini menunjukkan bahwa hotel berbintang berpotensi untuk dikembangkan karena minat wisatawan menggunakan akomodasinya cukup tinggi. Pengelolaan manajemen hotel berbintang yang baik diharapkan mampu memuaskan wisnu sebagai pengguna terbanyak sehingga dapat ikut berperan serta meningkatkan roda perekonomian DIY. Oleh sebab itu, perlu diketahui karakteristik wisnu yang memilih hotel berbintang sebagai tempat menginap selama berwisata ke DIY. Penelitian ini juga bertujuan untuk mengetahui apa saja perbedaan dan persamaan preferensi di antara wisnu saat mereka memilih menggunakan hotel berbintang. Dengan demikian, pengelola hotel dapat menentukan langkah strategis untuk mempertahankan dan meningkatkan pasar wisnu penggunaan kamar hotel berbintang.

\section{KAJIAN PUSTAKA \\ Preferensi Wisatawan}

Preferensi merupakan tindakan yang berada di antara motif dan perilaku. Preferensi wisatawan merupakan tindakan memilih di antara serangkaian pilihan yang dipengaruhi motivasi seseorang (Tran and Ralston, 2006:5). (Kolb, 2011:130) menjelaskan bahwa tahap evaluasi alternatif adalah tahap pemilihan produk yang paling sesuai dengan keinginan wisatawan dari berbagai produk pariwisata yang ditawarkan. Pengetahuan yang terkait dengan preferensi wisatawan dapat membantu penyedia produk pariwisata untuk menciptakan produk yang sesuai dengan keinginan wisatawan. Permintaan akan produk-produk pariwisata tersebut dapat mendorong kegiatan usaha pariwisata terus berkelanjutan.

\section{Faktor Internal Preferensi Wisatawan}

Preferensi pelanggan sangat tergantung pada variabel-variabel yang memengaruhi evaluasi dalam menentukan kualitas layanan yang mereka inginkan, seperti usia, pendidikan, pendapatan, dan gaya hidup (Ozimek et. al., 2017:172). Penelitian preferensi wisatawan yang dilakukan oleh Li et. al. (2013:328) di Hong Kong membuktikan adanya perbedaan preferensi wisatawan memilih hotel berdasarkan daerah asal dan kelompok wisatawan (wisatawan bisnis, pasangan, dan keluarga) terhadap lokasi, kualitas tidur, kualitas kamar, dan kebersihan.

Liu et. al. (2017:559) menemukan bahwa perbedaan bahasa atau latar belakang budaya memengaruhi perbedaan preferensi wisatawan terkait dengan pemilihan hotel pada atribut kualitas kamar, nilai, lokasi, kebersihan dan layanan. Namun demikian, secara keseluruhan wisatawan memberikan perhatian khusus pada kualitas kamar dan layanan hotel. Penelitian preferensi wisatawan dalam memilih akomodasi yang dilakukan oleh Lockyer dan Roberts (2009:24) menunjukkan bahwa pada saat wisatawan ingin menginap di motel yang berada di New Zealand terdapat faktor pemicu pemilihan motel, yaitu harga dan kebersihan motel. Kedua hal tersebut memengaruhi wisatawan dengan rencana lama tinggal yang berbeda (minimalist, essentials, dan enhancers). Ulasan wisatawan tentang fasilitas hotel yang pernah digunakannya sebagai tempat menginap berpengaruh cukup kuat bagi wisatawan lainnya dalam memilih hotel. Hal ini ditemukan dalam penelitian Chan et. al., (2017:56) yang menemukan bahwa preferensi wisatawan memilih fasilitas, amenitas, dan layanan hotel dipengaruhi oleh ulasan wisatawan sebelumnya yang pernah menggunakan hotel yang sama. Wisatawan yang membuat ulasan memiliki kesamaan latar belakang demografi dengan wisatawan pembaca ulasan.

\section{Faktor Eksternal Preferensi Wisatawan Penelitian Lockyer (2002:5)} menemukan bahwa terdapat perbedaan 
signifikan pada faktor-faktor yang memengaruhi pilihan akomodasi antara manajemen pengelola akomodasi dan tamu bisnis terkait dengan kualitas kamar mandi, standar kamar tidur, kenyamanan kamar tidur dan bantal, staf yang terlatih, sopan, antusias serta efisiensi front desk. Namun, keduanya menunjukkan bahwa kebersihan merupakan faktor yang memengaruhi pilihan akomodasi. Penelitian Lockyer (2005:481) mengungkap beberapa hal yang menjadi perhatian penting wisatawan sebelum memilih hotel, yaitu faktor lokasi, harga, fasilitas, dan kebersihan hotel. Penelitian Aksoy dan Ozbuk (2017:73), yang terkait dengan preferensi wisatawan, menjelaskan bahwa pada hal yang dipertimbangkan saat memilih lokasi hotel ialah jumlah atraksi wisata yang mudah dijangkau dengan berjalan kaki, aksesibilitas yang cukup dekat dengan stasiun dan pusat kota. Penelitian Liu dan He (2013:9) mengungkapkan bahwa lokasi hotel, informasi online, dan paket yang ditawarkan hotel-hotel di Amerika Serikat berdampak signifikan dengan pilihan wisatawan yang merupakan pelajar Johnson \& Wales University.

Perbedaan preferensi wisatawan juga dibuktikan dalam penelitian Schamel (2012:1117), yang menunjukkan bahwa wisatawan bisnis bersedia membayar harga yang lebih tinggi untuk hotel-hotel yang memiliki rating yang tinggi di situs pemesanan kamar online. Wisatawan ini juga bersedia ikut serta memberikan rating dan mereka juga suka memesan hotel secara online. Mereka menggunakan informasi dari ulasan online sebagai alat referensi untuk melihat apa yang sedang populer di konsumen lainnya untuk digunakan sebagai masukan bagi preferensi mereka sendiri (Tantrabundit, 2015:24). Selanjutnya, wisatawan dari berbagai usia menginginkan kualitas produk, harga yang menarik, keamanan, dan kenyamanan dalam memilih tempat untuk menginap (Ananth et. al., 1992:1). Penelitian yang terkait dengan preferensi wisatawan yang merupakan wanita pengusaha menunjukkan bahwa mereka mengutamakan keamanan dan lokasi saat memilih hotel (Hao dan Har, 2014:186).

Penelitian yang dilakukan Chaves et. al. (2012:1287) menunjukkan bahwa kamar, layanan staf dan kebersihan hotel merupakan konsep yang paling sering muncul dalam ulasan wisatawan. Penelitian yang terkait dengan kualitas layanan juga dilakukan oleh Sun et. al.
(2017:172) yang menunjukkan bahwa keyakinan kualitas layanan dengan brand hotel yang sama lebih baik di negara seperti negara Barat dan Hong kong daripada kualitas layanan di luar cina daripada di Cina.

Penelitian (Li et. al., 2015:319) menemukan bahwa tren preferensi wisatawan terus berkembang seiring dengan perkembangan zaman, fasilitas tambahan, seperti $c l u b$ dan makanan menjadi perhatian yang terus meningkat dari wisatawan, sedangkan perhatian pada harga, aksesibilitas, kebersihan, dan fasilitas lainnya menurun.

\section{METODE PENELITIAN}

Pendekatan kuantitatif digunakan untuk menjawab permasalahan penelitian. Pengujian teori yang tersusun atas variabel-variabel diukur dengan bilangan-bilangan dan dianalisis dengan prosedur statistik dengan tujuan menentukan generalisasi prediktif dari teori yang diselidiki terbukti kebenarannya (Trijono, 2015). Metode survei adalah metode pengumpulan data tentang populasi yang ingin diteliti dengan menggunakan himpunan bagian dari populasi tersebut (Stopher, 2012). Wisnu yang menginap di hotel-hotel berbintang di DIY adalah populasi penelitian. Penentuan populasi penelitian menggunakan data kunjungan wisnu per bulan yang dicatat oleh BPS DIY. Berdasarkan data tersebut, diketahui bahwa jumlah kunjungan wisnu setiap bulan berfluktuasi sehingga penentuan populasi menggunakan rata-rata jumlah kunjungan per bulan. Sampel penelitian merupakan wisnu yang kebetulan sedang menginap di berbagai kelas hotel berbintang di DIY selama bulan Oktober 2019. Preferensi wisatawan Nusantara pada hotel berbintang disusun menjadi dua belas variabel yang diukur keseluruhannya dengan bilangan. Hasil pengukuran yang diperoleh kemudian dianalisis dengan prosedur statistik agar mendapatkan jawaban pengujian dari teori yang diselidiki. Wisnu yang dipilih mempunyai sifat yang mewakili populasi agar hasil analisis dapat berlaku untuk seluruh anggota populasi (Utama, 2016). Dengan demikian, wisnu yang sudah memilih sendiri kamar hotel berbintang yang diinginkan dan merealisasikannya dengan menginap dianggap memiliki sifat yang mewakili populasi. 


\section{HASIL DAN PEMBAHASAN \\ Karakteristik Wisatawan}

Pengguna hotel berbintang di DIY berasal dari berbagai daerah di Indonesia mencakup Pulau Jawa dan luar Pulau Jawa. Jumlah pengguna hotel berjenis kelamin lakilaki dan perempuan hampir sama, dengan rentang usia wisnu beragam yaitu usia muda, dewasa dan tua. Pengguna hotel sebagian besar sudah bekerja dan memiliki latar belakang pekerjaan yang berbeda-beda, yaitu wiraswasta, pegawai pemerintah, pegawai swasta, dan sisanya merupakan mahasiswa. Pengguna hotel yang berwisata bersama keluarga atau bersama pasangan sedikit lebih banyak dibandingkan dengan yang berwisata dengan rekan atau sendiri. Sebelum memilih hotel tempat menginap, wisatawan yang memiliki tujuan untuk berkunjung ke objek wisata yang berada jauh dari pusat kota lebih besar jumlahnya dibandingkan dengan wisatawan yang ingin mengunjungi objek wisata yang dekat dengan kota. Lama tinggal wisatawan sebagian besar 2-5 hari, kemudian kurang dari 2 hari dan paling sedikit lebih dari 5 hari. Berdasarkan uji statistik yang dilakukan terhadap atribut hotel berbintang diperoleh hasil sebagai beriku (Lihat Tabel 1).

Tabel 1. Preferensi Wisnu terhadap Atribut Hotel

\begin{tabular}{|l|r|r|r|}
\hline $\begin{array}{l}\text { Preferensi } \\
\text { pemilihan } \\
\text { atribut }\end{array}$ & Setuju & $\begin{array}{l}\text { Tidak } \\
\text { setuju }\end{array}$ & $\begin{array}{l}\text { Total (N) } \\
(\%)\end{array}$ \\
\hline $\begin{array}{l}\text { Lokasi hotel } \\
\text { dekat pusat } \\
\text { kota }\end{array}$ & 73 & 27 & 100 \\
\hline Layanan hotel & 91 & 9 & 100 \\
\hline Kamar hotel & 62 & 38 & 100 \\
\hline $\begin{array}{l}\text { Fasilitas } \\
\text { tambahan hotel }\end{array}$ & 64 & 36 & 100 \\
\hline
\end{tabular}

Sumber: Data Primer, 2019 (Data Diolah)

Pengguna hotel sebagian besar setuju bahwa ulasan pengguna hotel berbintang sebelumnya memengaruhi preferensi mereka memilih hotel berbintang pada saat mereka melakukan perjalanan wisata ke DIY. Sebagian besar wisatawan juga setuju bahwa sebelum memilih sebuah hotel mereka mempertimbangkan lokasi, layanan, fasilitas dan fasilitas tambahan hotel sebagai bahan pertimbangan untuk memilih hotel berbintang.

\section{Perbedaan dan Persamaan Preferensi Wisatawan}

Perbedaan dan persamaan preferensi diukur dengan delapan variabel dan diperoleh hasil sebagai berikut (Lihat Tabel 2).

Tabel 2. Perbedaan dan Persamaan Preferensi Wisnu terhadap Atribut Hotel

Persamaan Preferensi

\begin{tabular}{|c|c|c|c|c|}
\hline Variabel & $\begin{array}{l}\text { Chi- } \\
\text { Square } \\
\text { Hitung }\end{array}$ & $\begin{array}{c}\text { Chi- } \\
\text { Square } \\
\text { Tabel }\end{array}$ & Probabilitas & Persamaan \\
\hline $\begin{array}{l}\text { Daerah } \\
\text { asal }\end{array}$ & $2,144^{\mathrm{a}}$ & 0,143 & 0,093 & lokasi \\
\hline $\begin{array}{l}\text { Daerah } \\
\text { asal }\end{array}$ & $1,099^{\mathrm{a}}$ & 0,295 & 0,245 & layanan \\
\hline $\begin{array}{l}\text { Daerah } \\
\text { asal }\end{array}$ & $1,528^{\mathrm{a}}$ & 0,216 & 0,166 & kamar \\
\hline $\begin{array}{l}\text { Daerah } \\
\text { asal }\end{array}$ & $2,127^{\mathrm{a}}$ & 0,145 & 0,095 & $\begin{array}{l}\text { fasilitas } \\
\text { tambahan }\end{array}$ \\
\hline Usia & $1,022^{\mathrm{a}}$ & 0,600 & 0,550 & lokasi \\
\hline Usia & $3,755^{\mathrm{a}}$ & 0,153 & 0,103 & $\begin{array}{l}\text { fasilitas } \\
\text { tambahan }\end{array}$ \\
\hline $\begin{array}{l}\text { Jenis } \\
\text { kelamin }\end{array}$ &, $728^{a}$ & 0,394 & 0,344 & lokasi \\
\hline $\begin{array}{l}\text { Jenis } \\
\text { kelamin }\end{array}$ &, $001^{\mathrm{a}}$ & 0,978 & 0,928 & layanan \\
\hline $\begin{array}{l}\text { Jenis } \\
\text { kelamin }\end{array}$ &, $895^{\mathrm{a}}$ & 0,344 & 0,294 & kamar \\
\hline Pekerjaan &, $039^{a}$ & 0,844 & 0,794 & lokasi \\
\hline Pekerjaan & $497^{a}$ & 0,481 & 0,431 & $\begin{array}{l}\text { fasilitas } \\
\text { tambahan }\end{array}$ \\
\hline $\begin{array}{l}\text { Mode } \\
\text { perjalanan }\end{array}$ & $271^{\mathrm{a}}$ & 0,603 & 0,553 & lokasi \\
\hline $\begin{array}{l}\text { Mode } \\
\text { perjalanan }\end{array}$ &, $001^{\mathrm{a}}$ & 0,972 & 0,922 & layanan \\
\hline $\begin{array}{l}\text { Mode } \\
\text { perjalanan }\end{array}$ & $1,442^{\mathrm{a}}$ & 0,230 & 0,180 & kamar \\
\hline $\begin{array}{l}\text { Objek } \\
\text { wisata }\end{array}$ & $1,801^{\mathrm{a}}$ & 0,180 & 0,130 & lokasi \\
\hline $\begin{array}{l}\text { Objek } \\
\text { wisata }\end{array}$ &, $049^{a}$ & 0,826 & 0,776 & layanan \\
\hline $\begin{array}{l}\text { Objek } \\
\text { wisata }\end{array}$ & $2,052^{\mathrm{a}}$ & 0,152 & 0,102 & kamar \\
\hline $\begin{array}{l}\text { Objek } \\
\text { wisata }\end{array}$ &, $104^{\mathrm{a}}$ & 0,748 & 0,698 & $\begin{array}{l}\text { fasilitas } \\
\text { tambahan }\end{array}$ \\
\hline $\begin{array}{l}\text { Lama } \\
\text { tinggal }\end{array}$ & $1,684^{\mathrm{a}}$ & 0,431 & 0,381 & lokasi \\
\hline $\begin{array}{l}\text { Lama } \\
\text { tinggal }\end{array}$ & $2,433^{\mathrm{a}}$ & 0,296 & 0,246 & layanan \\
\hline $\begin{array}{l}\text { Lama } \\
\text { tinggal }\end{array}$ & $361^{\mathrm{a}}$ & 0,835 & 0,785 & kamar \\
\hline $\begin{array}{l}\text { Lama } \\
\text { tinggal }\end{array}$ & $2,649^{\mathrm{a}}$ & 0,266 & 0,216 & $\begin{array}{l}\text { fasilitas } \\
\text { tambahan }\end{array}$ \\
\hline $\begin{array}{l}\text { Ulasan } \\
\text { tentang } \\
\text { hotel }\end{array}$ & $1,527^{\mathrm{a}}$ & 0,217 & 0,167 & lokasi \\
\hline $\begin{array}{l}\text { Ulasan } \\
\text { tentang } \\
\text { hotel }\end{array}$ & $306^{\mathrm{a}}$ & 0,580 & 0,530 & $\begin{array}{l}\text { fasilitas } \\
\text { tambahan }\end{array}$ \\
\hline
\end{tabular}


Perbedaan Preferensi

\begin{tabular}{|l|c|c|c|l|}
\hline Variabel & $\begin{array}{c}\text { Chi- } \\
\text { Square } \\
\text { Hitung }\end{array}$ & $\begin{array}{c}\text { Chi- } \\
\text { Square } \\
\text { Tabel }\end{array}$ & Probabilitas & Perbedaan \\
\hline Usia & $11,969^{\mathrm{a}}$ & 0,003 & 0,047 & layanan \\
\hline Usia & $8,577^{\mathrm{a}}$ & 0,014 & 0,036 & kamar \\
\hline $\begin{array}{l}\text { Jenis } \\
\text { kelamin }\end{array}$ & $6,008^{\mathrm{a}}$ & 0,014 & 0,036 & $\begin{array}{l}\text { fasilitas } \\
\text { tambahan }\end{array}$ \\
\hline Pekerjaan & $11,514^{\mathrm{a}}$ & 0,001 & 0,049 & layanan \\
\hline $\begin{array}{l}\text { Pekerjaan } \\
\text { Mode } \\
\text { perjalanan }\end{array}$ & $7,645^{\mathrm{a}}$ & 0,006 & 0,044 & kamar \\
\hline $\begin{array}{l}\text { Ulasan } \\
\text { tentang } \\
\text { hotel }\end{array}$ & $7,150^{\mathrm{a}}$ & 0,007 & 0,046 & $\begin{array}{l}\text { fasilitas } \\
\text { tambahan }\end{array}$ \\
\hline $\begin{array}{l}\text { Ulasan } \\
\text { tentang } \\
\text { hotel }\end{array}$ & $6,642^{\mathrm{a}}$ & 0,010 & 0,004 & \\
\hline \multicolumn{2}{|l|}{ Sumber: } & & 0,043 & layanan \\
\hline
\end{tabular}

Sumber: Data Primer, 2019 (Data Diolah)

Berdasarkan daerah asal, pilihan objek wisata dan lama tinggal wisatawan tidak ditemukan adanya perbedaan preferensi pada lokasi, layanan, fasilitas kamar, dan fasilitas tambahan hotel. Perbedaan preferensi wisatawan terdapat pada pemilihan fasilitas tambahan hotel yang dipengaruhi oleh jenis kelamin wisatawan. Perbedaan selanjutnya terdapat pada pemilihan hotel berdasarkan pelayanan hotel. Wisatawan yang sudah bekerja lebih banyak memberikan perhatian kepada atribut layanan dibandingkan dengan wisatawan yang berlatar belakang mahasiswa. Perbedaan preferensi antara wisatawan yang sudah bekerja dengan wisatawan berlatar belakang belum bekerja juga terlihat pada fasilitas hotel yang ditawarkan. Wisatawan yang belum bekerja atau mahasiswa tidak begitu memberikankan perhatian pada fasilitas hotel dibandingkan dengan wisatawan yang sudah bekerja. Perbedaan preferensi juga terdapat pada mode perjalanan dengan fasilitas tambahan hotel. Wisatawan yang membawa serta keluarga dan pasangan setuju bahwa mereka memberi perhatian pada fasilitas tambahan hotel sebelum melakukan pemesanan, dibandingkan dengan wisatawan yang bepergian sendiri atau bersama rekan. Perbedaan preferensi selanjutnya terdapat pada ulasan wisatawan terhadap layanan hotel. Wisatawan yang membaca ulasan wisatawan sebelumnya sebagian besar setuju bahwa ulasan tersebut memengaruhi preferensi mereka dalam pemilihan layanan dan fasilitas hotel.

\section{Pembahasan}

Penelitian terkait preferensi pengguna hotel diperlukan untuk mengetahui segmen pasar wisatawan, kemudian menentukan langkah strategis untuk peningkatan pasar wisatawan tersebut. Wisnu pengguna hotel berbintang berasal dari berbagai wilayah di Indonesia, baik luar Pulau Jawa maupun Pulau Jawa. Hal ini menunjukkan keberagaman pada pengguna hotel. Namun demikian, berdasarkan uji perbedaan yang dilakukan, tidak ditemukan adanya perbedaan preferensi wisnu terhadap pemilihan hotel berbintang berdasarkan latar belakang daerah asal wisatawan. Wisnu yang berasal dari Pulau Jawa atau luar Pulau Jawa, keduanya, dipengaruhi oleh lokasi, layanan, fasilitas, dan fasilitas tambahan hotel saat memilih hotel berbintang. Hasil penelitian ini berbeda dengan penelitian sebelumnya yang dilakukan oleh (Liu, 2017:559) yang membuktikan bahwa latar belakang budaya wisatawan memengaruhi perbedaan preferensi kualitas kamar, nilai, lokasi, kebersihan, dan layanan hotel.

Berdasarkan usia wisatawan terlihat adanya perbedaan preferensi pemilihan hotel yang dipengaruhi oleh layanan hotel. Wisnu berusia dewasa dan berusia lanjut memiliki preferensi pada layanan hotel sebelum melakukan pemesanan kamar hotel. Berbeda dengan wisatawan berusia remaja yang lebih praktis dan tidak begitu menitikberatkan layanan sebagai faktor penting pemilihan hotel mereka. Perbedaan preferensi pada layanan hotel ini perlu mendapatkan perhatian oleh pengelola hotel mengingat jumlah wisatawan berusia dewasa dan berusia lanjut memiliki persentase menginap yang cukup besar. Pengelola hotel perlu menjaga dan meningkatkan layanan hotel secara terusmenerus sehingga dapat mendorong peningkatan pemesanan kamar hotel. Perbedaan usia wisatawan juga menunjukkan adanya perbedaan preferensi pemilihan hotel yang dipengaruhi oleh fasilitas hotel. Sebagian besar wisnu berusia dewasa dan berusia lanjut setuju bahwa pemilihan hotel mereka dipengaruhi oleh fasilitas yang ditawarkan oleh hotel tersebut. Wisnu berusia remaja sebagian besar tidak setuju bahwa adanya fasilitas yang ditawarkan hotel berbintang memengaruhi preferensi pemilihan hotel. Perbedaan preferensi berdasarkan usia wisnu juga dibuktikan pada penelitian sebelumnya yang dilakukan oleh Ozimek (2017:179) yang menemukan bahwa 
terdapat perbedaan preferensi berdasarkan usia wisatawan terhadap layanan hotel.

Berdasarkan jenis kelamin wisatawan terdapat perbedaan pemilihan hotel yang dipengaruhi oleh fasilitas tambahan hotel. Sebagian besar wisnu perempuan setuju bahwa preferensi pemilihan hotel mereka dipengaruhi oleh fasilitas tambahan hotel. Mengingat jumlah pengguna laki-laki dan perempuan hampir sama jumlahnya di hotel berbintang, keberadaan fasilitas tambahan menjadi penting sebagai daya tarik bagi pengguna hotel. Perbedaan preferensi pada fasilitas tambahan hotel juga berbeda pada wisnu dengan mode perjalanan yang berbeda. Wisnu yang berwisata dengan mengajak serta keluarga dan pasangan setuju bahwa fasilitas tambahan hotel memengaruhi preferensi mereka saat memilih hotel. Sama seperti penelitian sebelumnya yang dilakukan (Li et. al.,2015:319) menemukan bahwa tren preferensi wisatawan terus berkembang seiring dengan perkembangan zaman, fasilitas tambahan, seperti club dan makanan yang disajikan. Pengelola hotel dituntut untuk terus berinovasi dengan menyajikan sesuatu yang unik dan berbeda, misalnya menyajikan makanan khas tradisional atau resep makanan khas yang ada di restoran hotel, atau membuat konsep hotel yang berbeda melalui dekorasi atau desain bangunan yang unik.

Berdasarkan latar belakang pekerjaan wisnu, preferensi wisnu juga menunjukkan perbedaan pada layanan hotel. Sebagian besar wisnu pengguna hotel berbintang yang berlatar belakang pekerja setuju bahwa layanan yang disediakan oleh hotel memengaruhi preferensi wisnu dalam memilih hotel. Berbeda dengan wisnu berlatar belakang belum bekerja atau mahasiswa yang tidak setuju bahwa layanan hotel memengaruhi preferensi mereka saat memilih kamar hotel. Perbedaan preferensi pada fasilitas hotel juga berbeda pada wisnu berlatar belakang pekerja dan mahasiswa. Wisnu berlatar belakang pekerja setuju bahwa fasilitas memengaruhi preferensi pemilihan hotel, berbeda dengan wisnu yang belum bekerja. Perbedaan ini sesuai dengan penelitian yang dilakukan oleh Ozimek et. al. (2017:172) bahwa latar belakang pendidikan memengaruhi perbedaan preferensi pemilihan hotel oleh wisatawan. Dengan demikian, pengelola hotel perlu terus menjaga kualiatas fasilitas dan layanan hotel agar tidak kehilangan segmen wisnu pekerja. Hal ini penting mengingat segmen wisnu pekerja jumlahnya sedikit lebih banyak dibandingkan segmen wisnu yang belum bekerja atau mahasiswa.

Ulasan wisnu sebelumnya juga menunjukkan perbedaan preferensi antara wisnu yang sering membaca ulasan dan tidak. Sebagian besar wisnu yang sering membaca ulasan setuju bahwa pemilihan hotel mereka dipengaruhi oleh ulasan tentang layanan dan fasilitas hotel wisnu sebelumnya. Hal ini sesuai dengan penelitian Chan et. al., (2017:56) yang menemukan bahwa preferensi wisatawan memilih fasilitas, amenitas, dan layanan hotel dipengaruhi oleh ulasan wisatawan sebelumnya yang pernah menggunakan hotel yang sama dan wisatawan yang membuat ulasan memiliki kesamaan latar belakang demografi dengan wisatawan pembaca ulasan. Pada era digital seperti saat ini, sangat wajar apabila teknik pemasaran jasa hotel sebagian besar ditawarkan melalui media online, baik itu online travel agent atau website dan media sosial yang dimiliki oleh hotel-hotel berbintang. Oleh sebab itu, perhatian mengenai ulasan yang diberikan wisnu setelah mereka menginap perlu mendapat perhatian penting dari pengelola hotel. Hal ini penting sebagai bahan masukan bagi peningkatan seluruh layanan dan fasilitas hotel. Selanjutnya ulasan yang baik tentang layanan dan fasilitas suatu hotel tertentu dapat membantu meningkatkan nilai hotel tersebut sehingga mendorong minat wisnu lainnya untuk memesan hotel yang sama.

\section{KESIMPULAN DAN SARAN Kesimpulan}

Penelitian ini bertujuan untuk mengetahui preferensi wisnu memilih hotel berbintang yang ada di DIY. Penelitian sebelumnya membuktikan bahwa usia, pendidikan, gaya hidup, pendapatan, karakteristik demografi, bahasa, rencana lama tinggal, jumlah atraksi wisata, dan mode perjalanan memengaruhi preferensi wisatawan memilih hotel. Hasil penelitian ini menunjukkan bahwa wisnu pengguna hotel berasal dari berbagai wilayah di Indonesia, lakilaki dan perempuan, rentang usia dari muda hingga tua, dan sebagian besar berwisata bersama keluarga atau pasangan. Hasil penelitian ini menunjukkan bahwa faktor usia, jenis kelamin, pekerjaan, mode perjalanan dan ulasan pengguna hotel sebelumnya memengaruhi perbedaan preferensi wisatawan saat memilih layanan, fasilitas utama, dan 
fasilitas tambahan hotel. Hal ini menunjukkan bahwa segmen pasar pengguna hotel berbintang cukup luas dan beragam.

\section{Saran}

Pengelola hotel perlu menjaga pasar yang sudah ada dengan menjaga dan meningkatkan layanan serta fasilitas utama. Pengelola hotel juga perlu memperhatikan adanya inovasi fasilitas tambahan hotel agar tidak membosankan bagi pengunjung, seperti penyajian makanan atau penambahan dan pembaruan fasilitas seperti lounge, restoran,

\section{DAFTAR PUSTAKA}

Aksoy, S., dan Ozbuk, M. Y. 2017. "Multiple Criteria Decision Making in Hotel Location:Does it Relate to Postpurchase Consumer Evaluations?". Tourism Management Perspectives, 22, 73-81.

Ananth, M., DeMicco, F. J., Moreo, P. J., dan Howey, R. M. 1992. "Marketplace Lodging Needs of Mature Travelers". Cornell Hotel and Restaurant Administration Quarterly, 33(4), 1-13.

Chan, I.C.C., Lam, L.W., Chow, C.W.C., dan Fong, L.H.N. 2017. "The Effect of Online Reviews on Hotel Booking Intention: The Role of Reader-Reviewer Similarity". International Journal of Hospitality Management, 66, 54-65.

Chaves, M.S., Gomes, R., dan Pedron, C. 2012. "Analysing Reviews in the Web 2.0:Small and Medium Hotels in Portugal". Tourism Management, 33(5), $1286-1287$.

Dinas Pariwisata Daerah Istimewa Yogyakarta, Statistik Kepariwisataan 2018. Retrieved October 24, 2019, from https://visitingjogja.com/19962/statistikpariwisata-diy-2018/

Hao, J.S.C dan Har, C.O.S. 2014. "A Study of Preferences of Business Female Travelers on the Selection of Accommodation. Procedia-Social and Behavioral Sciences, 144, 176-186.

Kolb, B.M. 2011. Tourism Marketing for Cities and Towns. Routledge. New York.

Li, G., Law, R., Vu, H. Q., dan Rong, J. 2013. "Discovering the Hotel Selection dan kolam renang. Pengelola hotel perlu meminta kepada pengguna hotel untuk memberikan ulasan terbaik mereka di situs-situs pemesanan kamar online atau media sosial lainnya. Ulasan pengguna hotel sebelumnya dapat menjadi cara yang efektif dalam promosi hotel karena terbukti hampir $90 \%$ pengguna hotel berbintang membaca ulasan pengguna hotel sebelumnya sebagai bahan pertimbangan pemesanan kamar hotel.

Preferences of Hong Kong Inbound Traveleres Using Choquet Integral". Tourism Management, 36, 321-330.

Li, G., Law, R., Vu, H.Q., Rong, J., dan Zhao, X.R. 2015. "Identifying Emerging Hotel Preferences Using Emerging Pattern Mining Technique". Tourism Management, 46, 311-321.

Liu, M dan He, R. 2013. "Factors Affecting Students' Decision of Hotel Selection". MBA Student Scholarship, 17, 1-11.

Liu, Y., Terchert, T., Rossi, M., Li, H. dan Hu, F. 2017. "Big Data for Big Insight; Investigating Languange-Spesific Drivers of Hotel Satisfaction with 412,784 User Generated Reviews". Tourism Management, 59, 554-563.

Lockyer, T. 2002. "Business Guests's Accommodation Selection: The View from Both Sides. International Journal of Contemporary Management", 14(6). 294-300.

Lockyer, T. 2005. "Understanding the Dynamics of the Hotel Accommodation Purchase Decision". International Journal of Contemporary Hospitality Management, 17(6), 481-492.

Lockyer, T., dan Roberts, L. 2009. "Motel Accommodation: Trigger Points to Guest Accommodation Selection". International Journal of Contemporary Hospitality Management, 21(1), 24-37.

Ozimek, I., Szlachciuk, J., Kulykovets, O., dan Przezdziecka-Czyzewska, N. 2017. "Factors Influencing the Choice and Quality Assessment of Hotel Facilities in Poland". Folia Oeconomica Stetinensia, 17(1), 171-181. 
Schamel, G. 2012. "Weekend vs. Midweek stays: Modelling Hotel Room Rates in a Small Market". International Journal of Hospitality Management, 31(4), 11131118.

Stopher, P. 2012. Collecting, Managing, and Assessing Data Using Sample Surveys. Cambridge University Press. New York.

Sun, S., Tong, K.T., dan Law, R. 2017. "Chinese Hotel Guest Perception of International Chain Hotels under the Same Hotel Brand in Different Travel Destinations: The Cases of Intercontinental and Sheraton". Journal of Vacation Marketing, 23(2),172-188.

Tantrabundit, Pongsatorn. 2015. "How Online Review and Rating Systems Affect Online Consumer Buying Behaviour in the Hotel Industry". Alliant International University. San Diego.

Tran, X dan Ralston, L. 2006. "Tourist Preference Influence of Unconscious Needs". Annals of Tourism Research, 33(2), 424--441.

Trijono, R. 2015. Metodologi Penelitian Kuantitatif. Papas Sinar Sinanti. Jakarta.

Utama, R.B.I. 2016. Metodologi Penelitian Pariwisata dan Hospitalitas (Dilengkapi Studi Kasus Penelitian). Pustaka Larasan. Bali. 